\title{
Rational Electrode-Electrolyte Design for Efficient Ammonia Electrosynthesis under Ambient Conditions
}

Bryan H. R. Suryanto, ${ }^{\dagger}$ Colin S. M. Kang, ${ }^{\dagger}$ Dabin Wang, ${ }^{\dagger}$ Changlong Xiao, ${ }^{\dagger}{ }^{\dagger}$ Fengling Zhou, Luis Miguel Azofra, ${ }^{\ddagger \odot}$ Luigi Cavallo, ${ }^{\ddagger 0}$ Xinyi Zhang, ${ }^{\dagger}$ and Douglas R. MacFarlane ${ }^{*}, \dagger$

${ }^{\dagger}$ School of Chemistry, Monash University, Clayton, Victoria 3800, Australia

${ }^{\ddagger}$ KAUST Catalysis Centre (KCC), King Abdullah University of Science and Technology, Thuwal 23955-6900, Saudi Arabia

Supporting Information

\begin{abstract}
Renewable energy-driven ammonia electrosynthesis by $\mathrm{N}_{2}$ reduction reaction (NRR) at ambient conditions is vital for sustainability of both the global population and energy demand. However, NRR under ambient conditions to date has been plagued with a low yield rate and selectivity $(<10 \%)$ due to the more favorable hydrogen evolution reaction (HER) in aqueous media. Herein, surface area enhanced $\alpha$-Fe nanorods grown on carbon fiber paper were used as NRR cathodes in an aprotic fluorinated solventionic liquid mixture. Through this design, significantly enhanced NRR activity with an $\mathrm{NH}_{3}$ yield rate of $\sim 2.35 \times 10^{-11} \mathrm{~mol} \mathrm{~s}^{-1} \mathrm{~cm}_{\mathrm{GSA}}{ }^{-2},\left(3.71 \times 10^{-13} \mathrm{~mol} \mathrm{~s}^{-1} \mathrm{~cm}_{\mathrm{ECSA}}{ }^{-2}\right)$ and

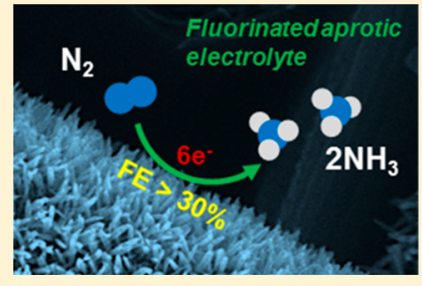
selectivity of $\sim 32 \%$ has been achieved under ambient conditions. This study reveals that the use of hydrophobic fluorinated aprotic electrolyte effectively limits the availability of protons and thus suppresses the competing HER. Therefore, electrode-electrolyte engineering is essential in advancing the $\mathrm{NH}_{3}$ electrosynthesis technology.
\end{abstract}

A nnually, an excess of 140 million tonnes of $\mathrm{NH}_{3}$ is produced industrially via the Haber-Bosch process, and the demand is growing. ${ }^{1,2}$ Ammonia plays a vital role in supporting global population owing to its role as an essential precursor in fertilizer production. However, the process is energetically demanding and associated with low efficiencies. Typical reaction requires temperatures and pressures of $\sim 500{ }^{\circ} \mathrm{C}$ and $>200 \mathrm{~atm}$ and the use of $\mathrm{Fe} / \mathrm{Ru}$ based catalysts. ${ }^{3,4}$ Therefore, it is estimated that $\sim 2 \%$ of the world's energy budget is spent on $\mathrm{NH}_{3}$ production. ${ }^{5}$ In addition, the process creates a substantial carbon footprint due to its dependence on steam reforming of natural gas. ${ }^{6}$

Electrochemical methods have a major role to play in the development of sustainable energy technologies. The method allows the direct conversion of renewable electricity (e.g., solar, wind) into chemical bonds. ${ }^{7}$ On the basis of this principle, $\mathrm{N}_{2}$ could be converted into $\mathrm{NH}_{3}$ through the $6 \mathrm{e}^{-}$process. Due to the known sluggish nitrogen reduction reaction (NRR) kinetics, $T>100{ }^{\circ} \mathrm{C}$ is often necessary; ${ }^{8}$ for example, a selectivity, otherwise known as the Faradaic efficiency (FE), of $78 \%$ has been reported at $570{ }^{\circ} \mathrm{C}$ using a Pd-based catalyst operating in a perovskite-based solid electrolyte. ${ }^{9}$

Nevertheless, electrochemical studies reported to date have yet to prove the feasibility of NRR at room temperature and pressure conditions (RTP). Hitherto, studies on NRR at RTP suffer from the drawbacks of low FE and NRR current density $\left(<5 \mu \mathrm{A} \mathrm{cm}^{-2}\right)$, indicating low $\mathrm{NH}_{3}$ yield rates of $10^{-11}-10^{-14}$ $\mathrm{mol} \mathrm{s} \mathrm{cm}^{-1} \mathrm{~cm}^{2,10-13}$ One of these studies was conducted by
Kordali et al., in which Pt was used as the cathode, achieving an $\mathrm{NH}_{3}$ yield rate of $3.1 \times 10^{-12} \mathrm{~mol} \mathrm{~s} \mathrm{~cm}^{-1}$, with a $\mathrm{FE}$ of $0.3 \%$ at $20{ }^{\circ} \mathrm{C}^{14}$ The main challenge for aqueous NRR is its low selectivity with respect to the HER due to the immediate availability of $\mathrm{H}^{+}$. In addition, although it remains debatable, the standard reduction potential of $\mathrm{N}_{2}$ is close to that for HER $^{15}$ Therefore, HER is a greatly favored electrochemical reduction reaction in aqueous media. It is shown that materials that exhibit weak adsorption for $\mathrm{H}^{+}\left(\Delta G_{\mathrm{M}-\mathrm{H}}>0 \mathrm{eV}\right)$ demonstrate improved activity for NRR. For example, Bao et al. used $\mathrm{Au}$ nanorods (NRs) $\left(\Delta G_{\mathrm{M}-\mathrm{H}}>0.3 \mathrm{eV}\right)^{16}$ as a NRR catalyst, delivering a maximum $\mathrm{NH}_{3}$ yield rate of $2.7 \times 10^{-11}$ mol s${ }^{-1} \mathrm{~cm}^{-2}$ and a FE of $4.0 \%{ }^{17}$ Further modifications of Aubased catalysts have demonstrated FEs as high as $10.1 \%{ }^{18,19}$ Other strategies include the use of alternate electrolyte media to enhance the NRR. ${ }^{6,20-22}$ We have recently demonstrated the use of aprotic, highly fluorinated ionic liquids (ILs) to limit the availability of $\mathrm{H}^{+} .{ }^{21}$ In addition, the fluorinated IL also exhibits a high $\mathrm{N}_{2}$ solubility, which therefore resulted in a highly efficient NRR with a $\mathrm{FE}$ as high as $60 \%{ }^{21}$ However, the $\mathrm{NH}_{3}$ yield rate was found to be in the range of $10^{-12} \mathrm{~mol} \mathrm{~s}^{-1} \mathrm{~cm}^{-2}$ due to the limited $\mathrm{N}_{2}$ mass transport in the viscous IL.

In this study, we employed a rational electrode-electrolyte design to improve the NRR selectivity, as supported by a

Received: March 25, 2018

Accepted: April 25, 2018

Published: April 25, 2018 
number of previous theoretical and experimental evaluations. ${ }^{20-24}$ Aprotic fluorinated solvent was used as an electrolyte in which the supply of $\mathrm{H}^{+}$can be regulated to favor $\mathrm{N}_{2}$ adsorption onto the catalytic sites. Additionally, the fluorinated solvents used are known to be both highly fluid and to have high gas solubility (e.g., perfluoroheptane has nearly twice the $\mathrm{N}_{2}$ solubility of heptane, 17 and $9.1 \mathrm{mmol} \mathrm{L}^{-1}$, respectively), while $\mathrm{H}_{2} \mathrm{O}$ exhibits a significantly lower $\mathrm{N}_{2}$ solubility of $0.66 \mathrm{mmol} \mathrm{L}^{-1} \cdot{ }^{25,26}$ However, these solvents generally show very poor solubility toward salts that are routinely used in aprotic electrolyte media. To counter this effect, a highly fluorinated IL salt, for example, 1-butyl-1methylpyrrolidinium tris(pentafluoroethyl)trifluorophosphate $\left(\left[\mathrm{C}_{4} \mathrm{mpyr}\right][\mathrm{eFAP}]\right)$ is shown to be highly soluble in the aprotic media in this work. Furthermore, the preparation of an Febased electrocatalyst by a direct hydrothermal deposition method is described. This minimizes the use of polymer binders that may disrupt electrocatalytic processes. The method also enables the achievement of a high-surface area Fe NR array structure, which is important for electrocatalysis.

Carbon fiber paper (CFP) was selected as an electrode substrate to grow the $\beta$-FeOOH NR due to the electrochemical inertness and its high porosity providing an enhanced active surface area (refer to the Supporting Information for details). Subsequently, $\beta$-FeOOH is reduced into a core-shell $\alpha$-Fe@ $\mathrm{Fe}_{3} \mathrm{O}_{4}$ by thermal annealing in $\mathrm{H}_{2}$ atmosphere. The successful synthesis of $\alpha$ - $\mathrm{Fe} @ \mathrm{Fe}_{3} \mathrm{O}_{4}$ was validated by X-ray diffraction (XRD) (refer to the Supporting Information for further details). Scanning electron microscopy (SEM) reveals the morphology of the synthesized $\beta$-FeOOH and $\alpha$-Fe NR. As shown in Figure $\mathrm{S} 1 \mathrm{a}, \mathrm{b}$, the $\beta$-FeOOH grows in a perpendicular direction against the CFP substrate, forming a dense array of NRs. The $\beta$-FeOOH exhibits an average diameter of $\sim 100-$ $150 \mathrm{~nm}$ and length of $\sim 500-1000 \mathrm{~nm}$. Following the thermal reduction to $\alpha$-Fe, the initially tubular NRs have transformed into an interconnected spherical particle morphology with a significantly reduced average diameter of $\sim 40-60 \mathrm{~nm}$ (Figure $1 \mathrm{a}, \mathrm{b})$. The significant size reductions suggest the removal of structural oxygen from the $\beta-\mathrm{FeOOH}$ crystal structure. Additionally, transmission electron microscopy (TEM) in Figure $1 \mathrm{c}, \mathrm{d}$ validates the formation of a core-shell $\alpha$-Fe@ $\mathrm{Fe}_{3} \mathrm{O}_{4}$ structure, showing an oxide thickness of $\sim 5 \mathrm{~nm}$.

Electrochemical measurements were conducted using the setup shown in Figure S2a. In designing the electrolyte for this work, we observed that $\left[\mathrm{C}_{4} \mathrm{mpyr}\right][\mathrm{eFAP}]$ was not miscible with some solvents (e.g., perfluoromethyldecalin and perfluorohexane); therefore, $1 \mathrm{H}, 1 \mathrm{H}, 5 \mathrm{H}$-octafluoropentyl-1,1,2,2-tetrafluoroethyl ether (FPEE) was chosen due to its high degree of fluorination and high miscibility with $\left[\mathrm{C}_{4}\right.$ mpyr $][\mathrm{eFAP}]$ (Figure $\mathrm{S} 2 \mathrm{~b})$. The physicochemical and electrochemical properties of FPEE, $\left[\mathrm{C}_{4} \mathrm{mpyr}\right][\mathrm{eFAP}]$, and their mixtures were characterized to determine the optimum solvent-IL ratio $\left(X_{\mathrm{IL}}\right)$ (please refer to section 3 of the Supporting Information for discussion). It is shown that the solvent-IL electrolyte system has a maximum conductivity of $1.95 \mathrm{mS} \mathrm{cm} \mathrm{cm}^{-1}$ and electrochemical window of $3.40 \mathrm{~V}$, ideal for NRR.

Figure 2a shows the cyclic voltammograms (CVs) collected with the $\alpha$-Fe@ $@ \mathrm{Fe}_{3} \mathrm{O}_{4} \mathrm{NR}$ cathode. The experiments were carried out at $X_{\mathrm{IL}}=0.16$, prepurged with either high-purity $\mathrm{N}_{2}$ gas $\left(99.999 \%\right.$ purity, $\left.C_{\mathrm{H} 2 \mathrm{O}}=\sim 20 \mathrm{ppm}\right)$ or Ar gas $(99.999 \%$ purity, $C_{\mathrm{H} 2 \mathrm{O}}=\sim 20 \mathrm{ppm}$ ) for $45 \mathrm{~min}$. Under a $\mathrm{N}_{2}$ atmosphere, the $\mathrm{CV}$ exhibited a cathodic shoulder with an onset of $-0.60 \mathrm{~V}$ vs NHE, while on the anodic sweep, an oxidation peak at -0.65
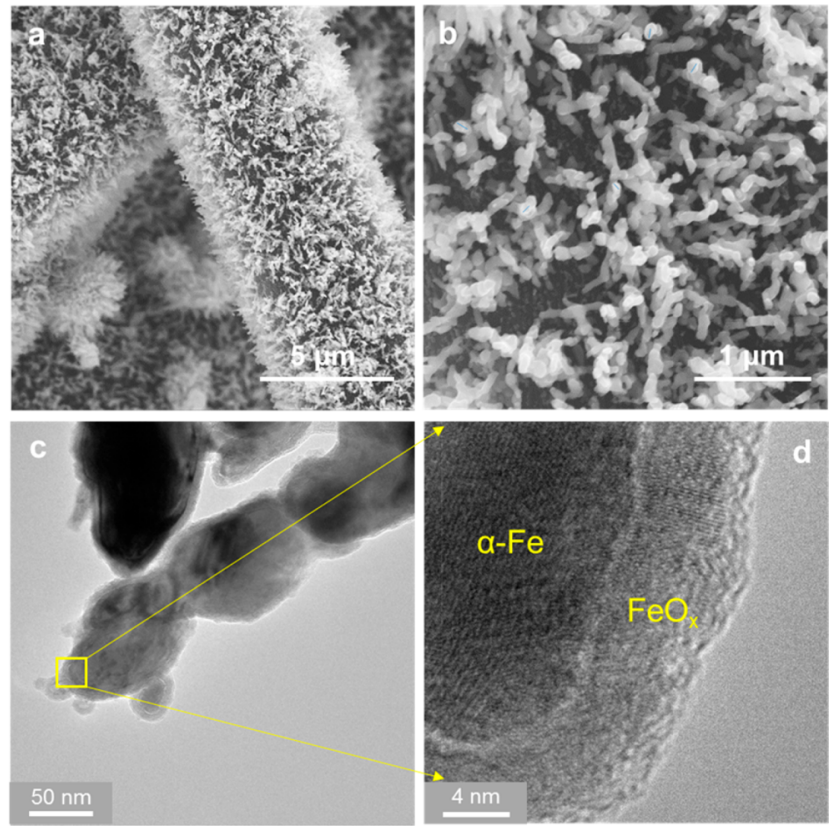

Figure 1. Scanning electron microscopy of $\alpha$-Fe@ $\mathrm{Fe}_{3} \mathrm{O}_{4}(\mathrm{a}, \mathrm{b})$ and the corresponding transmission electron microscopy $(\mathrm{c}, \mathrm{d})$.

$\mathrm{V}$ was observed. In contrast, the shoulder peak at $-0.60 \mathrm{~V}$ was not observed under an $\mathrm{Ar}$ atmosphere, signifying its ties to a $\mathrm{N}_{2}$ reduction event. However, the anodic peak at $-0.65 \mathrm{~V}$ was found to persist under Ar purging. To clarify the origin of the peak, CVs collected with different $C_{\mathrm{H} 2 \mathrm{O}}$ are also displayed. It is shown in Figure $2 \mathrm{a}$ that the anodic peak transforms proportionally with $\mathrm{C}_{\mathrm{H} 2 \mathrm{O}}$ (Figure $\mathrm{S} 3 \mathrm{~b}$ ) and is entirely absent in the dry Ar CV. The anodic peak can be related to the onset of HER at $E=-1.18 \mathrm{~V}$. Therefore, this process can be associated with the oxidation of $\mathrm{H}_{2}$ generated by the HER process that occurs during the cathodic sweep.

Electrochemical optimization was first conducted at $X_{\mathrm{IL}}=$ 0.16 , where the mixture exhibits a conductivity of $1.40 \mathrm{mS} \mathrm{cm}^{-1}$ (further discussions on conductivity and optimization are available in the sections 3 and 4 of the Supporting Information). NRR was carried out using controlled potential electrolysis (CPE). The possible $\mathrm{NH}_{3}$ contributions from impurities found in the IL, solutions, and gases, as well as possible electrochemical reduction of $\mathrm{NO}_{x}$, were initially determined by a series of control experiments, as shown in Supporting Information section 5 and Table S1. It is emphasized that such control/background experiments are vital in determining a reliable $\mathrm{NH}_{3}$ production rate in experiments such as these. CPE with different applied potentials ranging from -0.45 to $-0.75 \mathrm{~V}$ vs NHE were carried out, and the current transients are shown in Figure $2 \mathrm{~b}$. The highest $\mathrm{FE}$ and $\mathrm{NH}_{3}$ yield rate of $(11.0 \pm 0.6) \%$ and $(0.74$ $\pm 0.06) \times 10^{-11} \mathrm{~mol} \mathrm{~s}^{-1} \mathrm{~cm}^{-2}$, respectively, were achieved at an applied potential of $-0.65 \mathrm{~V}$. This potential is lower than the previously reported optimum NRR potential of $-0.8 \mathrm{~V}$ vs NHE on an electrodeposited $\mathrm{Fe}$ cathode in pure $\left[\mathrm{C}_{4} \mathrm{mpyr}\right][\mathrm{eFAP}]$. The application of a more negative potential of $-0.75 \mathrm{~V}$ resulted in a diminished $\mathrm{FE}$ and ammonia yield rate of $6.6 \pm$ $0.7 \%$ and $(0.65 \pm 0.06) \times 10^{-11} \mathrm{~mol} \mathrm{~s}^{-1} \mathrm{~m}^{-2}$. The decreases can be ascribed to the increased selectivity toward proton reduction/hydrogen evolution reaction (HER) at more negative potentials. ${ }^{6,21}$ 

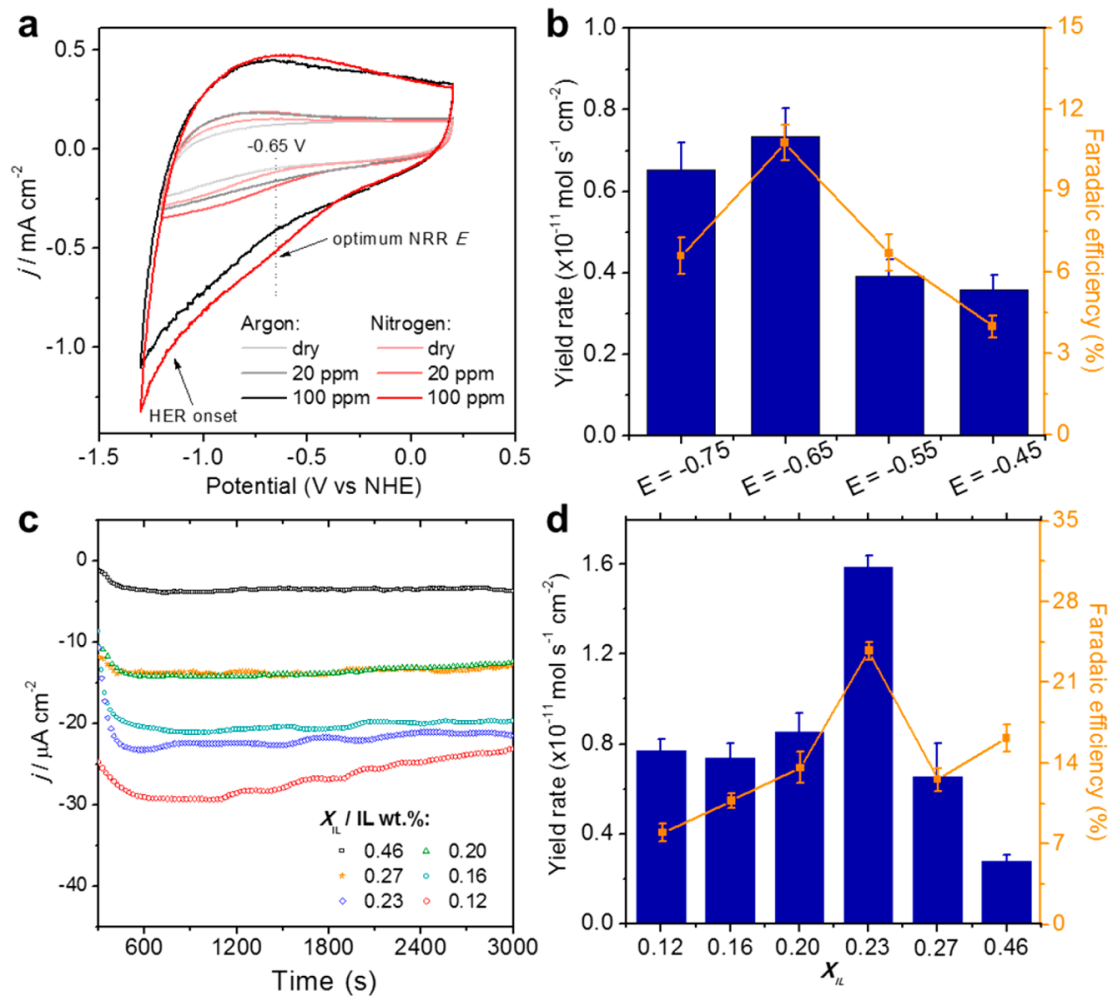

Figure 2. (a) Cyclic voltammogram analyses at $X_{\mathrm{IL}}=0.16$ in the presence of $\mathrm{N}_{2}$ and Ar gases with various $C_{\mathrm{H} 2 \mathrm{O}}$. (b) Potential dependence of the $\mathrm{NH}_{3}$ yield and $\mathrm{FE}(\%)$ at $X_{\mathrm{IL}}=0.16$. (c) Constant potential electrolysis at $-0.65 \mathrm{~V}$ vs NHE in various mixed electrolytes. (d) $X_{I L}$ dependence of the $\mathrm{NH}_{3}$ yield and $\mathrm{FE}(\%)$ at $-0.65 \mathrm{~V}$ vs NHE.

Recognizing the role of the IL mole fraction $\left(X_{\mathrm{IL}}\right)$ on the physicochemical properties of the electrolyte mixture, the NRR performance of the system was then further optimized for $X_{\mathrm{IL}}$. Figure $2 c$ shows the typical current density $(j)$ obtained in a range of different $X_{\mathrm{IL}}$. At a low $X_{\mathrm{IL}}$ of 0.16 , an average current density of $\sim 15 \mu \mathrm{A} \mathrm{cm}{ }^{-2}$ was observed, while the lowest current density of $\sim 3.5 \mu \mathrm{A} \mathrm{cm}^{-2}$ was exhibited at $X_{\mathrm{IL}}$ of 0.46 . A current density of $\sim 23 \mu \mathrm{A} \mathrm{cm}^{-2}$ was achieved at an $X_{\mathrm{IL}}$ of 0.23 . The variation of the $j$ could be dictated by several factors such as viscosity, conductivity, and $\mathrm{N}_{2}$ solubility. Figure $2 \mathrm{~d}$ shows that the highest $\mathrm{FE}$ of $23.8 \pm 0.8 \%$ with an $\mathrm{NH}_{3}$ yield rate of $1.58 \pm$ $0.05 \times 10^{-11} \mathrm{~mol} \mathrm{~s}^{-1} \mathrm{~cm}^{-2}$ was achieved at $X_{\mathrm{IL}}=0.23$ at the optimized potential of $-0.65 \mathrm{~V}$ vs NHE. To provide insight on the activity of the catalyst, the electrochemical active surface area (ECSA) of the $\alpha$-Fe@ $@ \mathrm{Fe}_{3} \mathrm{O}_{4}$ has been calculated (Figure S12), and the ECSA normalized $\mathrm{NH}_{3}$ yield rate is provided in Table S4. The highest $X_{\mathrm{IL}}$ tested in this series was 0.46 , exhibiting a $\mathrm{FE}$ of $16.2 \pm 1.2 \%$ and $\mathrm{NH}_{3}$ yield rate of $0.27 \pm$ $0.03 \times 10^{-11} \mathrm{~mol} \mathrm{~s}^{-1} \mathrm{~cm}^{-2}$. The significant drop of NRR performance with increasing $X_{\mathrm{IL}}$ signifies the important role of FPEE in supporting mass transport in this electrolyte. Other factors correlating FE to $X_{\mathrm{IL}}$ include the presence of complex molecular interactions and/or different diffusion behavior of neutral $\mathrm{N}_{2}$ molecules and polar $\mathrm{H}_{2} \mathrm{O}$ within the mixed electrolyte system. ${ }^{27}$ In addition, the electrochemical stability was also tested with CPE at the optimized condition, revealing a stable current profile for the testing period of $4 \mathrm{~h}$, as shown in Figure S8. By altering $C_{\mathrm{H} 2 \mathrm{O}}$ amount in the system (Figure S9 and Table S3), a $\mathrm{FE}$ as high as $30.8 \pm 1.6 \%$ and $\mathrm{NH}_{3}$ yield rate of $2.15 \pm 0.20 \times 10^{-11} \mathrm{~mol} \mathrm{~s}^{-1} \mathrm{~cm}^{-2}(n=4$ repeats, highest in the set $=2.35 \times 10^{-11} \mathrm{~mol} \mathrm{~s}^{-1} \mathrm{~cm}^{-2}$ and $\left.\mathrm{FE}=32 \%\right)$ could be achieved. It is worth noting that this value of the FE is significantly higher than most of the recent reports of NRR at RTP (Table S5). Finally, time-dependent NRR experiments shown by Figure $\mathrm{S} 10$ show that $\mathrm{NH}_{3}$ can be continuously produced with the application of longer electrolysis periods. The amount of produced $\mathrm{NH}_{3}$ is found to continuously increase at an approximately constant rate, after the first 30 min; the initial period may represent establishment of a steady state at the electrode. This result, in combination with the results of the control experiments listed in Table S1, validates the formation of $\mathrm{NH}_{3}$ from $\mathrm{NRR}$.

Density functional theory (DFT) investigations reveal that $\alpha$ Fe catalyzes the electrochemical conversion of $\mathrm{N}_{2}$ to $\mathrm{NH}_{3}$ at RTP; as shown in Figure 3a, NRR takes place on the (110) surface of $\alpha$-Fe via an associative distal pathway, ${ }^{4}$ entailing $\mathrm{N}_{2}$ adsorption and its further reduction by successive transfers of six $\mathrm{H}^{+}$and $\mathrm{e}^{-} \cdot \mathrm{N}_{2}$ interaction on a flat $\alpha$ - $\mathrm{Fe}(110)$ surface is estimated to be slightly physiosorbed with a binding Gibbs free energy of $-0.09 \mathrm{eV}$ and interatomic $\mathrm{N}-\mathrm{Fe}$ distance of $1.86 \AA$ (at the RPBE level, ${ }^{28}$ of calculations including Grimme D3 dispersion corrections; ${ }^{29}$ see full computational details in the Supporting Information). As a result of this, adsorbed $\mathrm{N}_{2}\left(* \mathrm{~N}_{2}\right)$ experiences elongation of the $\mathrm{N} \equiv \mathrm{N}$ triple bond by $0.02 \AA$ with respect to the calculated distance for an isolated $\mathrm{N}_{2}$ molecule in the gas phase; this could result in its activation for the following hydrogenation steps. Accordingly, the reaction Gibbs free energy for the first hydrogenation step $\left(* \mathrm{~N}_{2}+\mathrm{H}^{+} / \mathrm{e}^{-} \rightarrow\right.$ $* \mathrm{~N}_{2} \mathrm{H}$ ) is estimated to be only $0.15 \mathrm{eV}$ uphill after $\mathrm{N}_{2}$ adsorption. In this sense and contrary what has been predicted by Skúlason et al., ${ }^{15}$ the inclusion of D3 dispersion effects seems to have an important role in stabilization of the adsorbed $\mathrm{N}_{2} \mathrm{H}$ species. This stabilization by dispersion effects has been also corroborated with other methods such as Grimme D2 and 


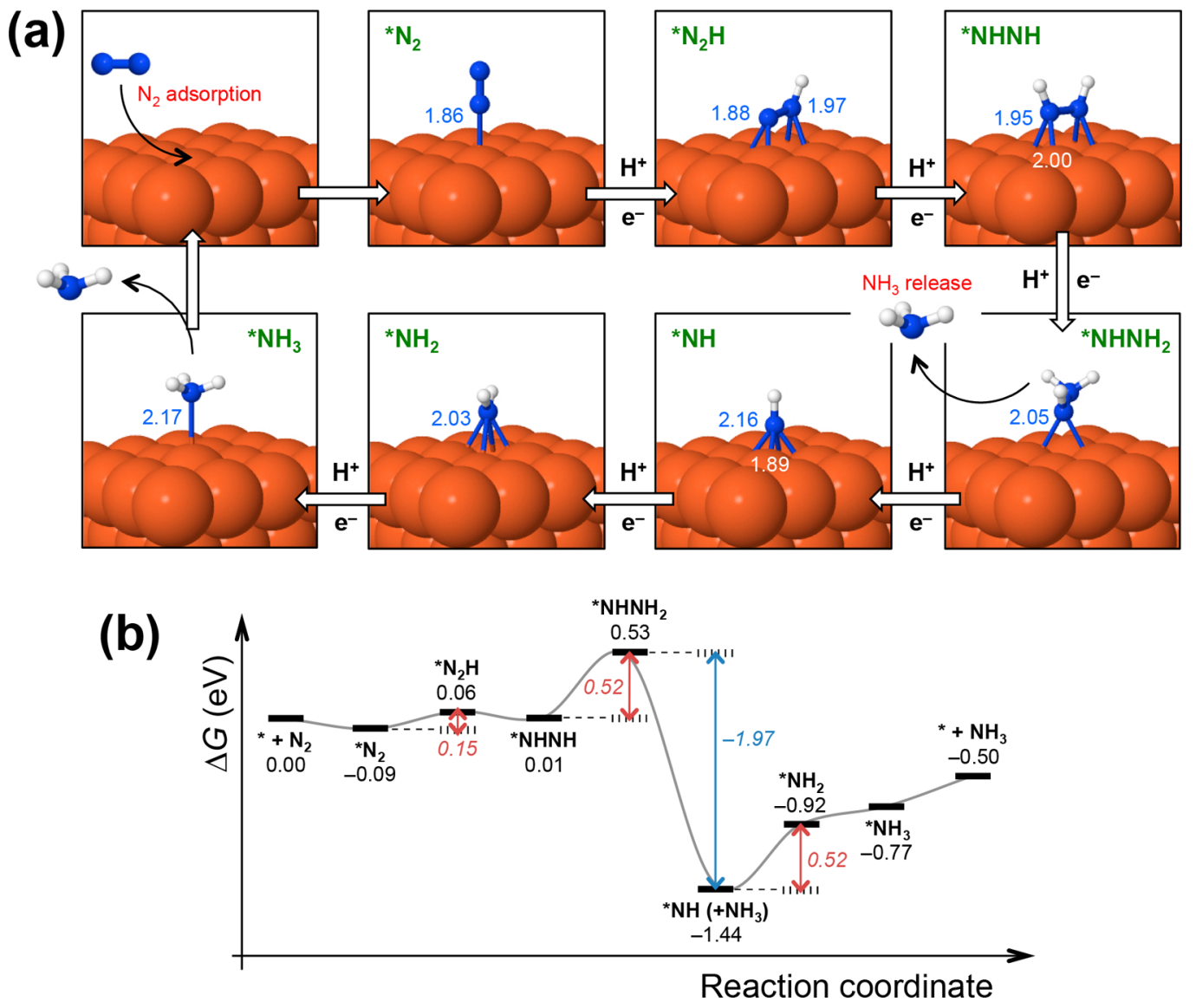

Figure 3. DFT analysis of the reaction mechanism at the RPBE level including D3 dispersion corrections. (a) Structures corresponding to the MEP for catalyzed NRR by an $\alpha$ - $\mathrm{Fe}(110)$ surface, with selected $\mathrm{N}-\mathrm{Fe}$ distances shown in $\AA$. (b) Gibbs free energies, in eV at RTP, for the associative distal pathway when there is no applied bias $(U=0 \mathrm{~V})$ and $\mathrm{pH}=0$. Gibbs free energy results, $\Delta G$, are referred to the computational hydrogen electrode by application of the PCET approach. Note: “*” denotes adsorbed species on the $\alpha$-Fe(110) surface. For selected cases, relative free energy changes, $\Delta \Delta G$, are indicated in red (endergonic) and blue (exergonic).

Tkatchenko-Scheffler. $^{30,31}$ This highlights the importance of the Fe-based catalytic process as compared with the first $\mathrm{H}^{+} / \mathrm{e}^{-}$ pair transfer from $\mathrm{N}_{2}$ to $\mathrm{N}_{2} \mathrm{H}$ in the gas phase, which is found experimentally to be $-3.2 \mathrm{~V}$ vs NHE and is usually the ratelimiting step of the whole reaction.

In-depth examination of the minimum-energy pathway (MEP) reveals that the second $\mathrm{H}^{+} / \mathrm{e}^{-}$pair transfer is produced on the unhydrogenated $\mathrm{N}$, leading to *NHNH (adsorbed cisdiazene), with a Gibbs free energy change of $-0.05 \mathrm{eV}$ relative to $* \mathrm{~N}_{2} \mathrm{H}$. During the third $\mathrm{H}^{+} / \mathrm{e}^{-}$pair transfer, the $* \mathrm{NHNH}_{2}$ intermediate species requires $0.52 \mathrm{eV}$ with respect to the adsorbed cis-diazene species. The first $\mathrm{NH}_{3}$ molecule is produced during the fourth $\mathrm{H}^{+} / \mathrm{e}^{-}$pair transfer as result of another hydrogenation on the $\mathrm{NH}_{2}$ moiety of $* \mathrm{NHNH}_{2}$. Therefore, generation of the $[\mathrm{Fe}]=\mathrm{NH}$ motif entails an energy drop of $1.97 \mathrm{eV}$, indicating it to be a very stable entity during the NRR cycle. ${ }^{32}$ Subsequently, relative Gibbs free energies for the successive fifth and sixth $\mathrm{H}^{+} / \mathrm{e}^{-}$gains to reach $* \mathrm{NH}_{2}$ and the final adsorbed $\mathrm{NH}_{3}$ species are calculated as 0.52 and 0.15 $\mathrm{eV}$, respectively. Finally, the reaction is completed by release of the second $\mathrm{NH}_{3}$ molecule, with an energy input of $0.27 \mathrm{eV}$.

For NRR, the first hydrogenation step $\left(* \mathrm{~N}_{2}+\mathrm{H}^{+} / \mathrm{e}^{-} \rightarrow\right.$ $* \mathrm{~N}_{2} \mathrm{H}$ ) usually represents the rate-limiting step of the whole reaction. Our DFT calculations including D3 dispersion corrections indicate that $* \mathrm{~N}_{2} \mathrm{H}$ formation is highly catalyzed by the $\alpha-\mathrm{Fe}(110)$ surface, requiring only $0.15 \mathrm{eV}$. In this regard, dispersion effects have an important stabilizing role in $\mathrm{N}_{2} \mathrm{H}$ adsorption. It is hypothesized that the most endergonic steps on $\alpha$-Fe(110) are instead the third (*NHNH $+\mathrm{H}^{+} / \mathrm{e}^{-} \rightarrow$ $\left.* \mathrm{NHNH}_{2}\right)$ and fifth $\left(* \mathrm{NH}+\mathrm{H}^{+} / \mathrm{e}^{-} \rightarrow * \mathrm{NH}_{2}\right)$ hydrogenations, in both cases with relative reaction Gibbs free energies, $\Delta \Delta G$, of $0.52 \mathrm{eV}$, as shown in Figure $3 \mathrm{~b}$.

In summary, we have shown that a high NRR FE of $32 \%$ and appreciable $\mathrm{NH}_{3}$ yield rate of $2.35 \times 10^{-11} \mathrm{~mol} \mathrm{~s}^{-1} \mathrm{~cm}^{-2}$ was achieved at RTP by rational design of the electrode-electrolyte system. First, it is demonstrated that the ability to regulate $\mathrm{H}^{+}$ in an aprotic solvent greatly enhances the FE due to the improved NRR selectivity over HER. Second, both experimental and DFT results show that $\alpha-\mathrm{Fe}(110)$ is an active surface for catalyzing NRR, and the core-shell structure of $\alpha$ $\mathrm{Fe} @ \mathrm{Fe}_{3} \mathrm{O}_{4}$ minimizes the loss of charge in the initial reduction of the $\mathrm{Fe}_{3} \mathrm{O}_{4}$ passivating shell. The reduction of $\alpha$-Fe@ $@ \mathrm{Fe}_{3} \mathrm{O}_{4}$ to form the active $\alpha$-Fe surface was also confirmed by post-NRR XRD characterization, Figure S11. DFT calculations have shown that $\mathrm{N}_{2}$ is slightly physisorbed on a flat $\alpha$ - $\mathrm{Fe}(110)$ surface, with a binding Gibbs free energy of $-0.09 \mathrm{eV}$ and interatomic $\mathrm{N}-\mathrm{Fe}$ distance of $1.86 \AA$. More remarkable is the stabilization with an important dose of dispersion of the first reduced $* \mathrm{~N}_{2} \mathrm{H}$ intermediate species, which is estimated to be only $0.15 \mathrm{eV}$ uphill with respect $\mathrm{N}_{2}$ adsorption. Among the previous DFT studies for NRR mechanisms, ${ }^{33} \alpha$-Fe(110) exhibits one of the smoother energy profiles, which accounts 
for the catalytic power of this material for electrochemical $\mathrm{N}_{2}$ conversion. Finally, this study has demonstrated, for the first time, the effectiveness of using a highly fluorinated solvent in supporting highly efficient RTP $\mathrm{NH}_{3}$ electrosynthesis.

\section{ASSOCIATED CONTENT}

\section{S Supporting Information}

The Supporting Information is available free of charge on the ACS Publications website at DOI: 10.1021/acsenergylett.8b00487.

Experimental details, XRD characterizations, physicochemical and electrochemical properties of evaluations, NRR optimizations, control experiments, NRR performance of $\mathrm{Fe}_{2} \mathrm{O}_{3}$ nanorods, supplementary figures, table of performance, and computational details (PDF)

\section{AUTHOR INFORMATION}

\section{Corresponding Author}

*E-mail: douglas.macfarlane@monash.edu.

\section{ORCID}

Bryan H. R. Suryanto: 0000-0001-9759-6362

Changlong Xiao: 0000-0001-5699-9018

Luis Miguel Azofra: 0000-0003-4974-1670

Luigi Cavallo: 0000-0002-1398-338X

Xinyi Zhang: 0000-0003-4695-3731

Notes

The authors declare no competing financial interest.

\section{ACKNOWLEDGMENTS}

The authors thank Monash Centre for Electron Microscopy (MCEM) for the provision of access to their instruments. L.M.A. and L.C. acknowledge King Abdullah University of Science and Technology (KAUST) for support. Gratitude is also due to the KAUST Supercomputing Laboratory using the supercomputer Shaheen II for providing the computational resources. This study was supported by an Australian Research Council (ARC) Discovery Grant (DP170102267). D.R.M. is grateful to the ARC for his Australian Laureate Fellowship.

\section{REFERENCES}

(1) Ober, J. A. U.S.G.S. Mineral Commodity Summaries 2017; U.S. Geological Survey, 2017.

(2) Chen, S.; Perathoner, S.; Ampelli, C.; Mebrahtu, C.; Su, D.; Centi, G. Electrocatalytic Synthesis of Ammonia at Room Temperature and Atmospheric Pressure from Water and Nitrogen on a Carbon Nanotube Based Electrocatalyst. Angew. Chem., Int. Ed. 2017, 56, 2699-2703.

(3) Kitano, M.; Kanbara, S.; Inoue, Y.; Kuganathan, N.; Sushko, P. V.; Yokoyama, T.; Hara, M.; Hosono, H. Electride Support Boosts Nitrogen Dissociation over Ruthenium Catalyst and Shifts the Bottleneck in Ammonia Synthesis. Nat. Commun. 2015, 6, 6731.

(4) Guo, C.; Ran, J.; Vasileff, A.; Qiao, S.-Z. Rational Design of Electrocatalysts and Photo(electro)catalysts for Nitrogen Reduction to Ammonia $\left(\mathrm{NH}_{3}\right)$ Under Ambient Conditions. Energy Environ. Sci. 2018, 11, 45-56.

(5) van der Ham, C. J.; Koper, M. T.; Hetterscheid, D. G. Challenges in Reduction of Dinitrogen by Proton and Electron Transfer. Chem. Soc. Rev. 2014, 43, 5183-5191.

(6) Singh, A. R.; Rohr, B. A.; Schwalbe, J. A.; Cargnello, M.; Chan, K.; Jaramillo, T. F.; Chorkendorff, I.; Nørskov, J. K. Electrochemical Ammonia Synthesis-The Selectivity Challenge. ACS Catal. 2017, 7, 706-709.
(7) Manthiram, A.; Vadivel Murugan, A.; Sarkar, A.; Muraliganth, T. Nanostructured Electrode Materials for Electrochemical Energy Storage and Conversion. Energy Environ. Sci. 2008, 1, 621-638.

(8) Kyriakou, V.; Garagounis, I.; Vasileiou, E.; Vourros, A.; Stoukides, M. Progress in the Electrochemical Synthesis of Ammonia. Catal. Today 2017, 286, 2-13.

(9) Marnellos, G.; Stoukides, M. Ammonia Synthesis at Atmospheric Pressure. Science 1998, 282, 98-100.

(10) Chen, G.-F.; Cao, X.; Wu, S.; Zeng, X.; Ding, L.-X.; Zhu, M.; Wang, H. Ammonia Electrosynthesis with High Selectivity under Ambient Conditions via a $\mathrm{Li}^{+}$Incorporation Strategy. J. Am. Chem. Soc. 2017, 139, 9771-9774.

(11) Kong, J.; Lim, A.; Yoon, C.; Jang, J. H.; Ham, H. C.; Han, J.; Nam, S.; Kim, D.; Sung, Y.-E.; Choi, J.; Park, H. S. Electrochemical Synthesis of $\mathrm{NH}_{3}$ at Low Temperature and Atmospheric Pressure Using a $\gamma-\mathrm{Fe}_{2} \mathrm{O}_{3}$ Catalyst. ACS Sustainable Chem. Eng. 2017, 5, 1098610995.

(12) Yang, D.; Chen, T.; Wang, Z. Electrochemical Reduction of Aqueous Nitrogen $\left(\mathrm{N}_{2}\right)$ at a Low Overpotential on (110)-oriented Mo nanofilm. J. Mater. Chem. A 2017, 5, 18967-18971.

(13) Köleli, F.; Kayan, D. B. Low Overpotential Reduction of Dinitrogen to Ammonia in Aqueous Media. J. Electroanal. Chem. 2010, $638,119-122$.

(14) Kordali, V.; Kyriacou, G.; Lambrou, C. Electrochemical Synthesis of Ammonia at Atmospheric Pressure and Low Temperature in a Solid Polymer Electrolyte Cell. Chem. Commun. 2000, 16731674.

(15) Skulason, E.; Bligaard, T.; Gudmundsdóttir, S.; Studt, F.; Rossmeisl, J.; Abild-Pedersen, F.; Vegge, T.; Jónsson, H.; Nørskov, J. K. A Theoretical Evaluation of Possible Transition Metal Electrocatalysts for $\mathrm{N}_{2}$ Reduction. Phys. Chem. Chem. Phys. 2012, 14, 12351245.

(16) Seh, Z. W.; Kibsgaard, J.; Dickens, C. F.; Chorkendorff, I.; Nørskov, J. K.; Jaramillo, T. F. Combining Theory and Experiment in Electrocatalysis: Insights into Materials Design. Science 2017, 355, eaad4998.

(17) Bao, D.; Zhang, Q.; Meng, F.-L.; Zhong, H.-X.; Shi, M.-M.; Zhang, Y.; Yan, J.-M.; Jiang, Q.; Zhang, X.-B. Electrochemical Reduction of $\mathrm{N}_{2}$ under Ambient Conditions for Artificial $\mathrm{N}_{2}$ Fixation and Renewable Energy Storage Using $\mathrm{N}_{2} / \mathrm{NH}_{3}$ Cycle. Adv. Mater. 2017, 29, 1604799.

(18) Li, S.-J.; Bao, D.; Shi, M.-M.; Wulan, B.-R.; Yan, J.-M.; Jiang, Q. Amorphizing of $\mathrm{Au}$ Nanoparticles by $\mathrm{CeO}_{\mathrm{x}}-\mathrm{RGO}$ Hybrid Support towards Highly Efficient Electrocatalyst for N2 Reduction under Ambient Conditions. Adv. Mater. 2017, 29, 1700001.

(19) Shi, M.-M.; Bao, D.; Wulan, B.-R.; Li, Y.-H.; Zhang, Y.-F.; Yan, J.-M.; Jiang, Q. Au Sub-Nanoclusters on $\mathrm{TiO}_{2}$ toward Highly Efficient and Selective Electrocatalyst for $\mathrm{N}_{2}$ Conversion to $\mathrm{NH}_{3}$ at Ambient Conditions. Adv. Mater. 2017, 29, 1606550.

(20) Kim, K.; Lee, N.; Yoo, C.-Y.; Kim, J.-N.; Yoon, H. C.; Han, J.-I. Communication-Electrochemical Reduction of Nitrogen to Ammonia in 2-Propanol under Ambient Temperature and Pressure. J. Electrochem. Soc. 2016, 163, F610-F612.

(21) Zhou, F.; Azofra, L. M.; Ali, M.; Kar, M.; Simonov, A. N.; McDonnell-Worth, C.; Sun, C.; Zhang, X.; MacFarlane, D. R. Electrosynthesis of Ammonia from Nitrogen at Ambient Temperature and Pressure in Ionic Liquids. Energy Environ. Sci. 2017, 10, 2516-2520.

(22) Köleli, F.; Röpke, T. Electrochemical Hydrogenation of Dinitrogen to Ammonia on a Polyaniline Electrode. Appl. Catal., $B$ 2006, 62, 306-310.

(23) Zhang, L.; Mallikarjun Sharada, S.; Singh, A. R.; Rohr, B. A.; Su, Y.; Qiao, L.; Nørskov, J. K. A Theoretical Study of the Effect of a Nonaqueous Proton Donor on Electrochemical Ammonia Synthesis. Phys. Chem. Chem. Phys. 2018, 20, 4982-4989.

(24) Abghoui, Y.; Garden, A. L.; Howalt, J. G.; Vegge, T.; Skulason, E. Electroreduction of $\mathrm{N}_{2}$ to Ammonia at Ambient Conditions on Mononitrides of $\mathrm{Zr}, \mathrm{Nb}, \mathrm{Cr}$, and V: A DFT Guide for Experiments. ACS Catal. 2016, 6, 635-646. 
(25) Wilhelm, E.; Battino, R. Thermodynamic Functions of the Solubilities of Gases in Liquids at $25^{\circ}$. Chem. Rev. 1973, 73, 1-9.

(26) Battino, R.; Rettich, T. R.; Tominaga, T. The Solubility of Nitrogen and Air in Liquids. J. Phys. Chem. Ref. Data 1984, 13, 563600.

(27) Araque, J. C.; Yadav, S. K.; Shadeck, M.; Maroncelli, M.; Margulis, C. J. How is Diffusion of Neutral and Charged Tracers Related to the Structure and Dynamics of a Room-Temperature Ionic Liquid? Large Deviations from Stokes-Einstein Behavior Explained. J. Phys. Chem. B 2015, 119, 7015-7029.

(28) Hammer, B.; Hansen, L. B.; Nørskov, J. K. Improved Adsorption Energetics Within Density-Functional Theory Using Revised Perdew-Burke-Ernzerhof Functionals. Phys. Rev. B: Condens. Matter Mater. Phys. 1999, 59, 7413-7421.

(29) Grimme, S.; Antony, J.; Ehrlich, S.; Krieg, H. A Consistent and Accurate $A b$ initio Parametrization of Density Functional Dispersion Correction (DFT-D) for the 94 Elements H-Pu. J. Chem. Phys. 2010, 132, 154104.

(30) Grimme, S. Semiempirical GGA-type Density Functional Constructed with a Long-range Dispersion Correction. J. Comput. Chem. 2006, 27, 1787-1799.

(31) Tkatchenko, A.; Scheffler, M. Accurate Molecular Van Der Waals Interactions from Ground-State Electron Density and FreeAtom Reference Data. Phys. Rev. Lett. 2009, 102, 073005.

(32) Montoya, J. H.; Tsai, C.; Vojvodic, A.; Nørskov, J. K. The Challenge of Electrochemical Ammonia Synthesis: A New Perspective on the Role of Nitrogen Scaling Relations. ChemSusChem 2015, 8, $2180-2186$

(33) Azofra, L. M.; Li, N.; MacFarlane, D. R.; Sun, C. Promising Prospects for $2 \mathrm{D} \mathrm{d} \mathrm{d}^{2}-\mathrm{d}^{4} \mathrm{M}_{3} \mathrm{C}_{2}$ Transition Metal Carbides (MXenes) in $\mathrm{N}_{2}$ Capture and Conversion into Ammonia. Energy Environ. Sci. 2016, 9, 2545-2549. 